\title{
Giải pháp mạnh xử lý cuộc khủng hoảng \\ RPE Discussion Papers 03 - 05
}

\begin{tabular}{|l|l|}
\hline Tác giả & $\begin{array}{l}\text { Pham Hùng Hiệp*, Trung tâm Nghiên cứu và Thực hành Giáo dục, Trường Đại học Dân lập } \\
\text { Phú Xuân; Phòng thí nghiệm AI về Dữ liệu xã hội (AI Social Data Lab) } \\
\text { * Tác giả liên hệ: phamhunghiep@ @mail.com, phamhunghiep@ @xu.edu.vn, 0975710565 }\end{array}$ \\
\hline Trích dẫn & $\begin{array}{l}\text { Nếu quý vị có nhu cầu trích dẫn bài này, xin vui lòng sử dụng trích dẫn theo chuẩn APA như } \\
\text { dưới đây: } \\
\text { Hiệp, P. H. (2017). "Giải pháp mạnh xử lý cuộc khủng hoảng." Retrieved 28/12, 2018, from } \\
\text { http://nhandan.com.vn/cuoituan/chuyen-de/item/33896102-giai-phap-manh-xu-ly-cuoc- } \\
\text { khung-hoang.html. }\end{array}$ \\
\hline Tóm tắt & $\begin{array}{l}\text { Một báo cáo trên tờ Independent của Anh cuối tháng } 6 \text { vừa qua cho biết, tại nước này trong } 5 \\
\text { năm qua đã và đang xảy ra hiện tượng nhiều giáo viên giỏi rời ngành, trong khi đầu vào lại có } \\
\text { xu hướng kém đi. Riêng năm 2016, con số chênh lệch giữa đầu ra và đầu vào là 2.600 giảng } \\
\text { viên giỏi trong toàn nước Anh. } \\
\text { Nghề giáo cũng không còn là nghề hấp dẫn thu hút được nhiều sinh viên giỏi tại Mỹ. Một bài } \\
\text { tường thuật đăng trên tờ Bưu điện Washington tháng 9-2016 cho thấy nước này đã thiếu } \\
\text { khoảng } 60 \text { nghìn giáo viên trong năm 2015. Từ năm 2009 đến 2014, quy mô đào tạo sư phạm } \\
\text { trong toàn nước Mỹ giảm từ } 691 \text { nghìn xuống còn 451 nghìn (giảm 35\%). Điều này hoàn toàn } \\
\text { trái ngược với xu thế quy mô học sinh sẽ tăng trong những năm tới. } \\
\text { Giải pháp trước mắt là xây dựng điểm sàn tạm thời } \\
\text { Giải pháp lâu dài là cần mạnh dạn xóa bỏ hoàn toàn việc đào tạo các mã ngành ĐH và CĐ sư } \\
\text { phạm, đồng thời biến các trường ĐH, CĐ sư phạm hiện nay, trước tiên thành các trường ĐH, } \\
\text { CĐ đào tạo bình thường. Bên cạnh đó, các thành phần (bao gồm giảng viên, chương trình...) } \\
\text { trước đây vốn phục vụ cho các chương trình cử nhân sư phạm nhu tâm lý, phương pháp giảng } \\
\text { dạy... sẽ được tái sắp xếp thành các khoa/trung tâm chuyên đào tạo về kỹ năng, nghiệp vụ sư } \\
\text { phạm. }\end{array}$ \\
\hline Tiáo dục, sư phạm, khủng khoảng, giải pháp \\
\hline khoá
\end{tabular}

RPE Discussion Papers tuyển chọn các bài nghiên cứu, phân tích, thảo luận về giáo dục các cấp tại Việt Nam và thế giới. Bản quyền bài viết thuộc về tác giả. Quan điểm trong bài viết thuộc về tác giả, không nhất thiết phản ánh quan điểm của Trung tâm RPE hay Trường Đại học Phú Xuân 


\section{PHU XUAN \\ UNIVERSITY}

Một báo cáo trên tờ Independent của Anh cuối tháng 6 vừa qua cho biết, tại nước này trong 5 năm qua đã và đang xảy ra hiện tượng nhiều giáo viên giỏi rời ngành, trong khi đầu vào lại có xu hướng kém đi. Riêng năm 2016, con số chênh lệch giữa đầu ra và đầu vào là 2.600 giảng viên giỏi trong toàn nước Anh.

Nghề giáo và ngành sư phạm không chỉ đang "gặp vấn đề" tại Việt Nam, mà thực tế nó đã là một vấn đề toàn cầu.

\section{Chênh lệch "đầu vào" - "đầu ra"}

Một báo cáo trên tờ Independent của Anh cuối tháng 6 vừa qua cho biết, tại nước này trong 5 năm qua đã và đang xảy ra hiện tượng nhiều giáo viên giỏi rời ngành, trong khi đầu vào lại có xu hướng kém đi. Riêng năm 2016, con số chênh lệch giữa đầu ra và đầu vào là 2.600 giảng viên giỏi trong toàn nước Anh.

Nghề giáo cũng không còn là nghề hấp dẫn thu hút được nhiều sinh viên giỏi tại Mỹ. Một bài tường thuật đăng trên tờ Bưu điện Washington tháng 9-2016 cho thấy nước này đã thiếu khoảng 60 nghìn giáo viên trong năm 2015. Từ năm 2009 đến 2014, quy mô đào tạo sư phạm trong toàn nước Mỹ giảm từ 691 nghìn xuống còn 451 nghìn (giảm $35 \%$ ). Điều này hoàn toàn trái ngược với xu thế quy mô học sinh sẽ tăng trong những năm tới.

Hậu quả nhãn tiền của việc này là nguy cơ dẫn đến chất lượng đào tạo giảm: tỷ lệ học sinh/giáo viên tăng cao; tăng quy mô lớp học và việc buộc phải tuyển giáo viên không được đào tạo bài bản về sư phạm.

Tại Việt Nam, trong thực tế, khủng hoảng đã đến với ngành sư phạm từ nhiều năm nay. Với riêng điểm chuẩn đầu vào ngành sư phạm, cũng không phải năm nay mới có hiện tượng điểm chuẩn thấp. Trong một vài năm gần đây, điểm chuẩn đầu vào tại một số trường $Đ H$ và $\mathrm{CĐ}$ Sư phạm đều rất thấp (ở mức bằng hoặc hơn một chút so với điểm sàn).

Cuộc khủng hoảng nghề giáo trên phạm vi toàn cầu, trong đó có Việt Nam, đến từ nhiều nguyên nhân cả khách quan lẫn chủ quan. Sự bùng nổ dân số trong mấy chục năm vừa qua, dẫn đến việc số lượng học sinh tăng nhanh "chóng mặt", điều này dẫn đến sức ép khủng khiếp đối với toàn bộ hệ thống giáo dục của tất cả các quốc gia. 
Trong bối cảnh đó, về chủ quan, chính sách đãi ngộ không có quá nhiều thay đổi đáng kể. Mức đầu tư cho ngành giáo dục không theo kịp mức độ tăng của quy mô dẫn đến việc nghề giáo không còn là nghề hấp dẫn bởi mức lương thiếu cạnh tranh, sức ép công việc lớn hơn (nhất là từ kỳ vọng ngày càng nhiều hơn của toàn xã hội) và những thay đổi về phương pháp giảng dạy, ứng dụng công nghệ dường như vẫn chưa giúp giáo viên thật sự giảm tải và bớt áp lực hơn.

\section{Giải pháp trước mắt}

Đối diện với khủng hoảng nghề giáo, mà cụ thể là việc tuyển đầu vào thấp, Bộ Giáo dục và Đào tạo (GD-ĐT) mới đây đã công bố, trong năm 2018 trở đi sẽ có điểm chuẩn riêng cho ngành sư phạm. Theo quan điểm cá nhân của người viết, đây chỉ là một giải pháp tạm thời. Không những thế, biện pháp này đang đi ngược với chủ trương chung từ trước đó là: xóa bỏ điểm sàn và trả lại quyền tự chủ (trong đó có tự chủ tuyển sinh đầu vào) cho các cơ sở đào tạo.

Tất nhiên, với mục đích xoa dịu dư luận (đang rất nóng và dường như không thể kiên nhẫn chờ đợi lâu hơn) thì giải pháp "điểm sàn riêng” cũng sẽ có cái lý của nó. Tuy vậy, trong ngắn hạn, cần điều chỉnh một chút về "điểm sàn riêng" này. Cụ thể, chúng ta cần nhớ, toàn bộ sinh viên ngành sư phạm đều được Nhà nước hỗ trợ $100 \%$ phí đào tạo, tức là không phải đóng học phí (trong khi sinh viên trường công thông thường được hỗ trợ khoảng 50\%; sinh viên trường tư và sinh viên trường tự chủ thì phải tự đóng học phí $100 \%$ ). Trong bối cảnh đó, việc điều chỉnh điểm sàn riêng cho ngành học này nên được xây dựng theo hướng là từ 2018, sẽ có điểm sàn cho ngành sư phạm đối với sinh viên được Nhà nước hỗ trợ học phí. Với sinh viên dưới mức điểm sàn này, các trường sư phạm vẫn có thể tuyển (nếu cảm thấy phù hợp) nhưng sẽ phải tự đóng học phí hoàn toàn (như sinh viên trường tư hoặc trường công tự chủ tài chính) hoặc một phần (như sinh viên trường công thông thường). 


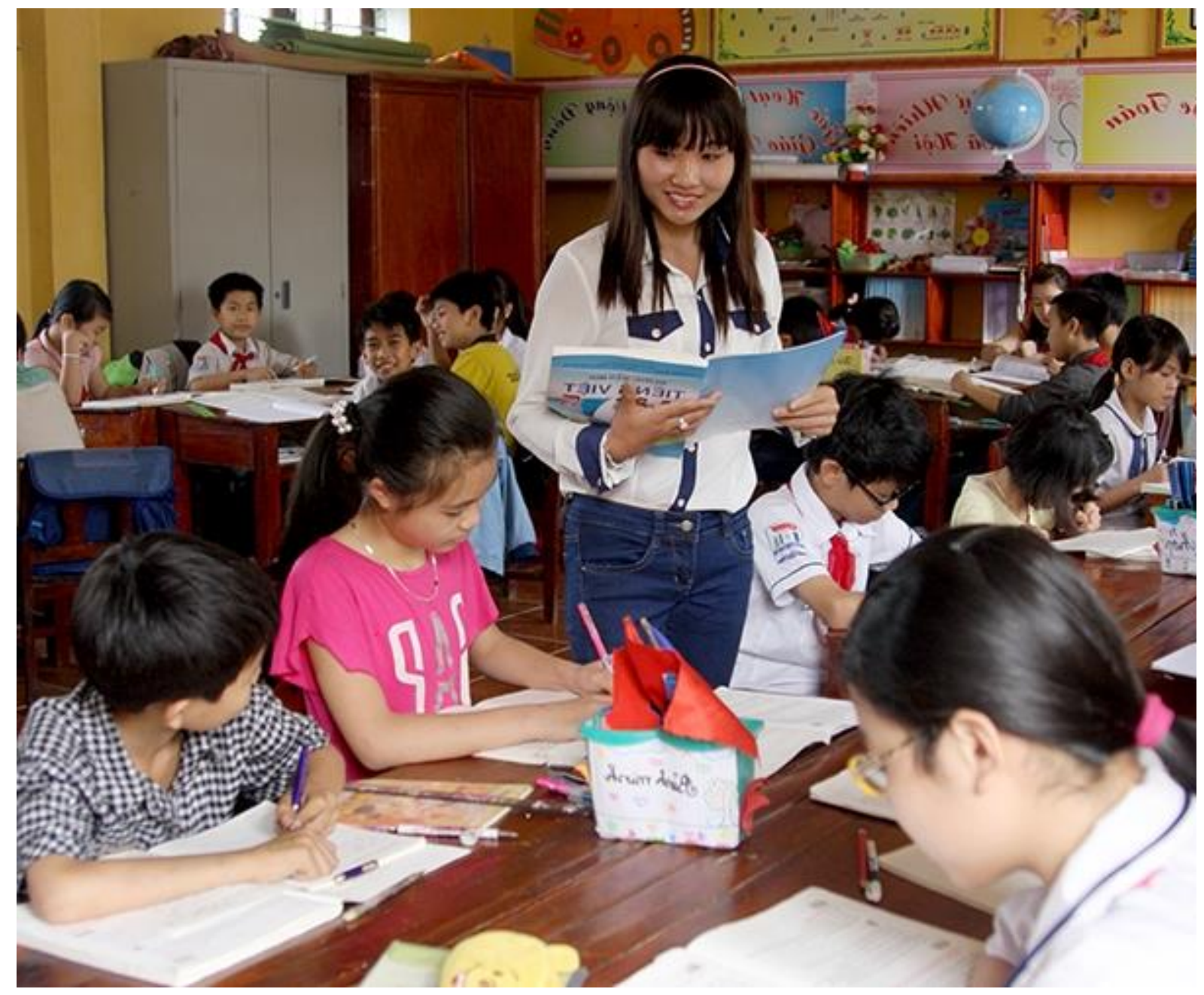

Biện pháp “điểm sàn” để được nhận hỗ trợ học phí kể trên, thực tế cũng chỉ là một giải pháp tạm thời cho một vấn đề đối với đào tạo sư phạm từ lâu, mà ít người để ý, đó là: "đầu tư không hiệu quả”. Thực vậy, thật vô lý nếu phải dùng tiền Nhà nước để đầu tư cho một sinh viên sư phạm với điểm đầu vào chỉ 15,5 trong khi một sinh viên học một ngành rất quan trọng là nông nghiệp tại Học viện Nông nghiệp Hà Nội với điểm đầu vào 25 thì lại không được hỗ trợ một đồng nào (Học viện Nông nghiệp đã tự chủ tài chính từ năm 2015). Như vậy, một mức “điểm sàn” để được nhận hỗ trợ học phí đủ cao (thí dụ 22 điểm trở lên) sẽ giúp giải bài toán đầu tư không hiệu quả.

Tuy vậy, như đã nói ở trên, đây cũng chỉ là một giải pháp tạm thời; bởi không có gì bảo đảm một sinh viên sư phạm 22 điểm sau bốn năm học sẽ làm đúng nghề giáo viên (rất tiếc chúng ta không có thống kê về tỷ lệ sinh viên tốt nghiệp sư phạm làm nghề giáo viên). 


\section{PHU XUAN \\ UNIVERSITY}

\section{Giải pháp lâu dài}

Được biết, hiện nay Chính phủ và Bộ GD-ĐT đang triển khai Đề án đổi mới các trường đại học sư phạm. Người viết bài này xin mạnh dạn đề xuất một giải pháp sẽ giúp cải cách thật sự triệt để, hay nói như ngôn ngữ báo chí là có thể "giải cứu nghề giáo".

Cụ thể, cần mạnh dạn xóa bỏ hoàn toàn việc đào tạo các mã ngành $Đ H$ và $\mathrm{CĐ}$ sư phạm, đồng thời biến các trường $\mathrm{ÐH}, \mathrm{CĐ}$ sư phạm hiện nay, trước tiên thành các trường $Đ H$, $\mathrm{C} Đ$ đào tạo bình thường. Điều đó có nghĩa là các trường sư phạm hiện nay cần phải hoạt động như một đại học công bình thường (tự chủ tài chính hoặc không tùy theo định hướng từng trường).

Bên cạnh đó, các thành phần (bao gồm giảng viên, chương trình...) trước đây vốn phục vụ cho các chương trình cử nhân sư phạm như tâm lý, phương pháp giảng dạy... sẽ được tái sắp xếp thành các khoa/trung tâm chuyên đào tạo về kỹ năng, nghiệp vụ sư phạm. Nhà nước hằng năm sẽ tổ chức một kỳ thi chứng chỉ nghề nghiệp sư phạm để trở thành giáo viên, và các thí sinh muốn tham gia kỳ thi này sẽ cần phải trải qua một khóa học trước đó tại các khoa/trung tâm kể trên trong khoảng $1-1,5$ năm (tùy thiết kế chương trình). Học phí theo học tại các chương trình này sẽ do Nhà nước hỗ trợ một phần hoặc toàn phần (thí dụ toàn phần với thí sinh sau này đỗ điểm cao, một phần với thí sinh đỗ).

Giải pháp trên, ban đầu có thể "gây sốc", nhưng thực tế lại khá nhẹ nhàng, bởi ngay lập tức, không dẫn đến việc buộc phải tinh giản biên chế hay sáp nhập đơn vị, tổ chức. Nhưng về lâu dài, giải pháp này sẽ vừa hiệu quả về tài chính (chỉ đầu tư cho những người xứng đáng), vừa kích thích được sự năng động của các trường $Đ H, C Đ$ sư phạm, vốn đã rất thiếu động lực và sức ép đổi mới như hiện nay. Thực tế, trên thế giới cũng đã có rất nhiều nước (thí dụ Pháp, Singapore, Ân Độ) cũng đã áp dụng phương thức tương tự.

Tất nhiên, bên cạnh giải pháp về tổ chức (xóa bỏ ngành cử nhân sư phạm, tái cấu trúc các trường $\mathrm{ÐH}, \mathrm{CĐ}$ sư phạm) và đầu tư như kể trên, chúng ta cũng không nên bỏ qua các giải pháp nhằm tăng cường năng lực chuyên môn cho đội ngũ giảng viên dạy các môn về sư phạm như ứng dụng công nghệ trong đào tạo, phương pháp giảng dạy mới (thuyết kiến tạo, lớp học đảo ngược). 